\title{
Morele vorming en filosofie opnieuw met elkaar verbinden'

\author{
Reconnecting moral education and philosophy
}

Natascha Kienstra

Department of Practical Theology and Religious Studies

Tilburg School of Catholic Theology

Universiteit van Tilburg

E-pos: n.h.h.kienstra@uvt.nl

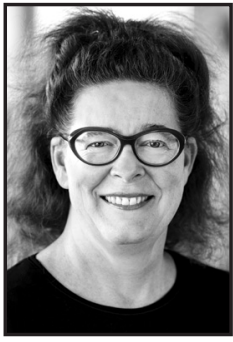

Natascha Kienstra

Natascha Kienstra is medeprofessor, filosofe en die onderrig van godsdienwetenskap en wêreldbeskouing by die Katolieke Teologiese Skool aan die Universiteit van Tilburg in Nederland. Sy het gepromoveer by die Fakulteit Filosofie aan die Universiteit van Radboud in Nijmegen (Nederland), en sy is ook vir die afgelope meer as 20 jaar ' $n$ dosent in didaktiese filosofie aan hierdie universiteit. In haar empiriese navorsing fokus sy op onderrig en die bemeestering van filosofie, etiek, godsdiens, en wêreldbeskouings. Sy is hoofnavorser in die Erasmusplus-projek, wat die etiek van Europese onderrig ondersoek (Community of Ethics Teachers, COMET), en sy ontwikkel 'n gesamentlike metodologie vir leraars in filosofie en afrigters van debatvoering (A Debate And Philosophy Typology, ADAPT). Sy is visie-president van die Association Internationale des Professeurs de Philosophie en publiseer gereeld in Religious Education, en PLOS ONE.
Natascha Kienstra is Assistant Professor of Philosophy, and of religious and worldview education at the School of Catholic Theology, Tilburg University, the Netherlands. She holds a doctorate from the Faculty of Philosophy at Radboud University in Nijmegen (the Netherlands), and for more than 20 years she has been a Didactics of Philosophy teacher at this university. Her empirical research focuses on teaching and learning philosophy, ethics, religion, and worldviews. She is the principal investigator in an Erasmusplus-project, which investigates European ethics education (Community of Ethics Teachers, COMET), and develops a joint methodology for philosophy teachers and debate coaches (A Debate And Philosophy Typology, ADAPT). She is vice-president of the Association Internationale des Professeurs de Philosophie and publishes regularly in Religious Education, and PLOSONE.

Deze publicatie is medegefinancierd met steun van de Europese Commissie. Deze publicatie geeft enkel de visie van de auteur weer, en de Commissie kan niet verantwoordelijk worden gesteld voor het gebruik dat eventueel wordt gemaakt van de informatie die erin is vervat (COMET 2-project nr. 2020-1-NL01-KA201-064702 en ADAPT-project nr. 2019-1-NL01-KA201-060287).

Datums:
Ontvang: 2021-05-18 Goedgekeur: 2021-10-01 $\quad$ Gepubliseer: Desember 2021




\section{ABSTRACT}

\section{Reconnecting moral education and philosophy}

Tilburg University in The Netherlands is distinct from other Dutch universities because it is intent on character formation as an educational goal and offers general philosophy classes to support such character formation. However, these courses focus more on theoretical knowledge than on actual practical competencies and actions. Both these components can be seen as "moral education". My core argument is that moral education should be taught in philosophy classes and my aim is to offer tools as to how to teach both components.

In section 2, building on Martha Nussbaum, I will place moral education in a context of different ways of learning ethics. There is more than one way of learning ethics, in which an ordering can be seen from theory to practice. Learning ethics ranges from cognitive learning, through reflection and through judgments, to moral action and moral education:

- learning ethics as knowledge-oriented

- learning ethics as reflection-oriented

- learning ethics as moral judgement-oriented

- learning ethics as competencelaction-oriented.

The latter ways of learning ethics receive less attention in education and these are precisely the ways Nussbaum focuses on.

I will argue that moral education has two components: a cognitive and skills component, and an attitude component. For the cognitive and skills component, we discuss the task of the philosophy teacher as well as characteristics of effective philosophy lessons derived from empirical research. Thus, I reconnect moral education and philosophy. Reconnect, in the sense that here I make a (new) connection via empiricism.

In section 3, I will outline the teacher's pedagogical task. Teaching scaffolds are important in guiding students through the learning process. Feedback involves the direct evaluation of students' behaviour, whereas hints entail providing clues regarding a given topic (and the deliberate withholding of a complete solution); instructing encompasses requesting a specific action or supplying information so that students understand what to do and how. Likewise, explaining involves providing information concerning how and why. Modelling encompasses demonstrating a behaviour for the purpose of imitation; questioning entails prompting students to think, or to request a specific reaction. In research on the above guiding skills, it has been found within religious and worldview lessons (where moral education also takes place) that in addition to the aforementioned scaffolds, the specific contribution of an effective teacher is to show understanding, give space, and listen. In doing so, it is ensured that learners can form their own opinions. To do this, students will need to be encouraged to think. Of course, moral education does not aim to realise, let alone impose, a unitary view in students, because moral action is always partly dependent on the individual situation and the social context.

In section 4, building on John Dewey and Hannah Arendt, I will provide characteristics of effective philosophy lessons derived from empirical research. In How we think, Dewey explains what he means by the thinking that he believes should be trained in education. He defines reflective thought as "active, persistent and careful consideration of any belief or supposed form of knowledge in the light of the grounds that support it, and the further conclusions to which it tends".

This kind of thinking corresponds to the notion of producing criticism and reflecting in my own research on doing philosophy effectively. There I argue that doing philosophy occurs in phases during a lesson. To qualify such a moment, we propose the Pearl Model. Pearls 
have different layers and these layers of pearls represent five philosophical activities: rationalising, analysing, testing, producing criticism, and reflecting. These activities are ordered hierarchically and conditionally. This indicates, for example, that while rationalising exists at a lower level than reflecting, reaching the level of reflection assumes that rationalising also has taken place. Therefore, the higher the level that a pearl reaches and the more layers have been achieved, the more thorough the philosophical understanding, and the more effectiveness of doing philosophy are acknowledged. Metaphorically, a pearl "shines" if the level of reflection has been reached while doing philosophy. A quantitative correspondence analysis yielded a scale that contrasts more from less effective lessons. In particular, we have found students to produce a higher level of doing philosophy with teachers who chose to organize a philosophical discussion with shared guidance, i.e. guidance by the teacher and the students.

Here we find the answer to Arendt's initial question whether the activity of thinking could be the condition that makes men abstain from evil-doing: from this thinking, and dialogue, conscience and the ability to judge are effected. Earlier in this paper I indicated that learning ethics ranges from learning ethics as knowledge-oriented, through learning ethics as reflectionoriented and through learning ethics as moral judgment-oriented, to learning ethics as competence/action-oriented. I arrive at the following position here: doing philosophy effectively can be classified as learning ethics as moral judgement-oriented. This is the first component of moral education, focusing on cognition and skills.

In section 5, building on Pierre Hadot, I will propose the good as exercise that shapes character: doing good can be classified as learning ethics as competence/action-oriented. This is the second component of moral education, focusing on attitudes. This brings us to another dimension of philosophy, which has to do with the question whether philosophy is something theoretical or rather an attitude. Hadot shows that while Aristotle makes a distinction between theoretical and practical wisdom, this certainly does not imply a separation between the two. That is to say, theoretical wisdom is not completely separated from human life; similarly, practical wisdom is not merely and solely an application of theoretical insights to practice. Moral action and philosophy thus require action in addition to thought: an amalgamation of knowledge, insight, skills, and attitudes.

In conclusion, I offer some tools that enable learning ethics in different ways. Supported by research from faculties where character formation is core business, philosophy and theology, we can work on the moral education of students. Not only will students and their teachers benefit, but also the community around the students (e.g., peers and family) and their professional practices (pastoral care, justice, defense, spiritual care, and education) will share in such achievement.

KEYWORDS: debate, dialogue, discussion, effective philosophy lessons, empirical research, ethics, learning ethics, ethics education, doing philosophy, philosophy, philosophy teacher, character building, character formation, moral action, moral education, exercise, education, judging, practical wisdom, reflecting, theology

TREFWOORDEN: debat, dialogeren, discussie, effectieve filosofielessen, empirisch onderzoek, ethiek, ethiek leren, ethiekonderwijs, filosoferen, filosofie, filosofiedocent, karaktervorming, moreel handelen, morele vorming, oefening, onderwijs, oordelen, praktische wijsheid, reflecteren, theologie 


\section{OPSOMMING}

Studenten van de Universiteit van Tilburg onderscheiden zich van die van andere universiteiten doordat er in hun opleiding veel aandacht wordt besteed aan karaktervorming. Op welke manier kunnen docenten studenten helpen om hun karakter te vormen? Kern van mijn betoog is dat morele vorming hierbij een belangrijke rol speelt en dat filosofiedocenten bij uitstek ertoe doen om de morele vorming plaats te laten vinden. Morele vorming en filosofie worden door mij opnieuw met elkaar verbonden, in de zin dat een verbinding via de empirie wordt gemaakt. Ik zal voortbouwend op Martha Nussbaum morele vorming plaatsen in een context van verschillende manieren van ethiek leren; de pedagogische taak van de docent schetsen; voortbouwend op John Dewey en Hannah Arendt empirisch onderzochte kenmerken geven van effectieve filosofielessen; en voortbouwend op Pierre Hadot het goede als oefening die het karakter vormt voorstellen. Zo kunnen we, ondersteund door onderzoek uit faculteiten waar karaktervorming tot de kern behoort, filosofie en theologie, werken aan de morele vorming van studenten. Niet alleen studenten en hun docenten zullen hiervan profiteren, maar ook de gemeenschap rond de studenten (bijvoorbeeld leeftijdgenoten en familie) en hun beroepspraktijken (pastoraat, justitie, defensie, geestelijke verzorging en onderwijs).

\section{Inleiding}

De Karaktervormingsleerlijn (KVL) BA-Theologie (2018) aan de Tilburg School of Catholic Theology (TST) is de uitwerking van de derde $\mathrm{K}$ van het Tilburg Education Profile (TEP 2021), namelijk de K van "karakter" naast de K van "kennis" (vakinhoudelijk) en de K van "kunde" (of skills: academische vaardigheden). Voor een concrete uitwerking van de KVL in de TST-bachelor cursussen die aansluit bij de slogan "Tilburg University: universiteit voor verantwoordelijke en ondernemende denkers" (TiU 2021) is de driedeling van "verantwoordelijkheid" van Jacques Derrida (2005:250-252) gehanteerd: répondre de, répondre à en répondre devant. "Bij répondre de gaat het om de verantwoordelijkheid die op jezelf betrokken is, om waarborgen en ergens voor staan in de vorm van zelfreflectie en zelfverantwoordelijkheid. Répondre à omvat het antwoorden of reageren op unieke concrete situaties, vragen, personen. Répondre devant betekent rekenschap afleggen voor een forum” (KVL 2018:2), zoals de academische gemeenschap, kerk, samenleving, toekomstige generaties. Voor zulke fora moet een student ook rekenschap afleggen.

In de TST Memo Bestuurlijke reactie Visitatierapport Onderwijs (Van Dijk-Groeneboer, 2020:2) staat het advies uit het eindrapport van de Visitatiecommissie Onderwijs opgenomen: "De commissie waardeert de bijdrage aan karaktervorming en raadt de TST aan zich hiermee te onderscheiden: het ontwikkelen van een eigen gedragen visie omtrent karaktervorming wordt aangemoedigd, door theoretische onderbouwing en de goede praktijken te gebruiken om daarmee een transparant en breed gedragen beleid op te bouwen, waarbij karaktervorming ook een plaats in de toetsing krijgt." De TST Memo Bestuurlijke reactie Visitatierapport Onderwijs kent een aangehecht werkplan (versie november 2020) waarin karaktervorming op vijf plaatsen is opgenomen in de planning 2020-2025.

In deze context stel ik de vraag hoe je dit doel, karaktervorming, kunt realiseren: op welke manier kunnen docenten studenten helpen om hun karakter te vormen? Kern van mijn betoog is dat morele vorming hierbij een belangrijke rol speelt en dat filosofiedocenten bij uitstek ertoe doen om de morele vorming plaats te laten vinden (Kienstra, 2016:235; Kienstra \& Van der Heijden, 2018). 
Wat wordt er met "morele vorming" bedoeld? Morele vorming is een operationalisering van karaktervorming. Karaktervorming is een verzamelbegrip waarbij het accent bijvoorbeeld ook kan vallen op persoonsvorming (Biesta, 2015), identiteitsvorming of burgerschapsvorming (Heijstek-Hofman et al., 2020). Bij morele vorming gaat het "niet puur om opgedane kennis van ethische stromingen, zoals utilisme, plichtethiek of deugdethiek" (Schoone, 2021:303). Studenten kunnen op een tentamen "prima uitleggen wat deze begrippen betekenen zonder dat ze daardoor opeens goede mensen zijn. Niet dat kennis van deze stromingen onbelangrijk is, maar er is meer nodig dan alleen deze kennis" (Schoone, 2021:303-304). Ik wil de lezer graag meenemen in mijn empirische onderzoek dat zich op het snijvlak bevindt van filosofie, theologie, ethiek en onderwijs, en waarin ik probeer om kennis van ethische theorieën te verbinden met persoonlijke morele reflectie en vorming.

Het paper kent de volgende opbouw. In sectie 2 zal ik voortbouwend op Martha Nussbaum morele vorming plaatsen in een context van verschillende manieren van ethiek leren. In sectie 3 zal ik de pedagogische taak van de docent schetsen. In sectie 4 zal ik voortbouwend op John Dewey en Hannah Arendt empirisch onderzochte kenmerken geven van effectieve filosofielessen en in sectie 5 voortbouwend op Pierre Hadot het goede als oefening die het karakter vormt voorstellen. Tot besluit geef ik enkele handreikingen die het mogelijk maken om op verschillende manieren ethiek te leren.

\section{Verschillende manieren van ethiek leren}

Ethiekonderwijs speelt een belangrijke rol bij de bevordering van waarden. Ethiek wordt echter bestudeerd binnen een grote verscheidenheid aan curricula. Op de TST bijvoorbeeld in vakken als ethiek, godsdienst/levensbeschouwelijk onderwijs, morele denkpatronen en filosofie. In andere TiU Schools is de situatie vergelijkbaar: (filosofische) reflectie op ethiek en morele waarden maken deel uit van verschillende cursussen in zowel BA- als MA-programma's. Al deze ethiek-cursussen bevatten veel informatie over morele theorieën, maar doen nauwelijks iets aan morele vorming.

Er is sprake van versnippering van ethiekonderwijs in de verschillende curricula, en samen met een versnippering van pedagogische methoden en doelstellingen, belemmert dit de mogelijkheden voor de uitwisseling van beste praktijken en wederzijds leren vooral waar het de morele vorming betreft. De Community of Ethics Teachers in Europe (COMET 1, 2021; COMET 2, 2021) beoogt deze curriculaire versnippering te overwinnen door middel van digitale innovatie, om zo de verwerving van vaardigheden en competenties van Europese ethiekdocenten te bevorderen.

Tijdens een eerste COMET project (2017-2020) werden de benaderingen voor het onderwijzen van ethiek gepresenteerd op een online platform (ethics.community 2021). Het onderzoek was erop gericht de curricula op het gebied van ethiek van de deelnemende Europese landen in kaart te brengen en te categoriseren (Kienstra \& Velema, 2018, 2019). Een van de opmerkelijke bevindingen van het COMET-project was dat geen van de deelnemende landen een alomvattende gespreksmethodologie bij het vak ethiek hanteerde: hoewel discussies over ethische onderwerpen gebruikelijk waren, ontbrak een meer systematische aanpak van het debatteren over morele dilemma's. Dit is opmerkelijk, omdat tegelijkertijd veel studies het positieve effect van debatteren hebben aangetoond op de morele vorming van de deelnemers (Rogers, 2002; Valkering et al., 2017:24). In verscheidene deelnemende landen vormt morele vorming de kern van het ethiekcurriculum en bevat de vaardigheden die onderdeel zijn van die vorming, zoals kritisch denken, empathie en respect voor verschillende standpunten. 
Tijdens een tweede COMET-project (2020-2023) is het onderzoek gericht op hoe men het eigen vermogen om goed na te denken vergroot door over morele dilemma's te discussiëren, te onderzoeken, te reflecteren, te argumenteren en te debatteren; medeburgers te erkennen als mensen met gelijke rechten; bezorgd te zijn om het leven van anderen; zich een goed beeld te vormen van een verscheidenheid aan complexe kwesties die van invloed zijn op het verhaal van een mensenleven; na te denken over het welzijn van de natie als geheel; de eigen natie op haar beurt te zien als een onderdeel van een gecompliceerde wereld (als in Nussbaum, 2010:2526).

Er zijn meer manieren om ethiek te leren waarbij een ordening te zien is van theorie naar praktijk (Kienstra, 2020a). Ethiek leren reikt van cognitief leren, via reflecteren en via oordelen, naar moreel handelen en morele vorming:

- learning ethics as knowledge-oriented

- learning ethics as reflection-oriented

- learning ethics as moral judgement-oriented

- learning ethics as competence/action-oriented.

De latere manieren van ethiek leren krijgen in het onderwijs minder aandacht en dit zijn juist de manieren waarop Nussbaum zich focust.

Ik zal hieronder betogen dat morele vorming twee componenten kent, een cognitieve en vaardigheidscomponent en een attitude component. Bij de cognitieve en vaardigheidscomponent bespreek ik de filosofiedocent en komen empirisch onderzochte kenmerken van effectieve filosofielessen aan de orde. Aldus verbind ik morele vorming en filosofie opnieuw met elkaar. Opnieuw, in de zin dat ik hier een (nieuwe) verbinding via de empirie maak.

\section{Pedagogische taak van de docent}

De verschillende manieren van ethiek leren hebben gevolgen voor de pedagogische taak van de filosofiedocent. Filosofie betekent liefde voor de wijsheid en die liefde kan op verschillende manieren worden uitgelegd (Kienstra, 2021a:162). Victoria Harrison (2020) legt in haar tekst "Realigning Philosophy and Wisdom in the $21^{\text {st }}$ Century" het verschil tussen geliefden en vrienden van de wijsheid op de volgende wijze uit: liefde voor de wijsheid verwacht te veel van filosofieleerlingen en louter het bestuderen van de filosofie verwacht te weinig van hen, maar vriendschap sluiten met de wijsheid is een goed midden tussen deze uitersten. Zij baseert zich hiervoor op Rhett Gayle (2011) die in zijn tekst "Befriending Wisdom" stelt dat in het onderwijzen van filosofie vorm gecombineerd moet worden met inhoud. Dat wil zeggen dat filosofische (denk)vaardigheden (filosoferen) gekoppeld moeten worden aan kennisinhouden (Kienstra, 2016:13). Verder zouden filosofen als vrienden van de wijsheid anderen moeten uitnodigen om een soortgelijke vriendschap aan te gaan.

Om leerders goed te kunnen begeleiden in hun leerproces, spreken Van de Pol, Volman, en Beishuizen (2010, 2011) over het belang van scaffolding. Docenten maken in hun lessen gebruik van feeding back, hinting, instructing, explaining, modeling en questioning. Met feedback wordt directe evaluatie van het gedrag/werk van de leerder bedoeld. Onder hints wordt verstaan: aanwijzingen geven met betrekking tot het onderwerp, of opzettelijk niet de hele oplossing geven. Instructie gaat over het geven van informatie zodat de leerders weten wat te doen en hoe, of om het vragen om een speciale actie. Er is sprake van uitleg als het waarom wordt toegelicht. Modeleren is gedrag voordoen om na te doen. Onder vragen wordt verstaan: vragen stellen die denken uitlokken, of vragen om een speciale reactie. In onderzoek 
naar bovenstaande begeleidingsvaardigheden is binnen lessen godsdienst en levensbeschouwing (waar ook morele vorming plaatsvindt) gevonden dat naast de eerdergenoemde scaffolds de specifieke bijdrage van een effectieve leraar het tonen van begrip, het geven van ruimte en het luisteren is, om zo te zorgen dat leerders hun eigen opvattingen kunnen vormen (Kienstra et al., 2018, Kienstra, 2019:213). De studenten zullen hiervoor aan het denken moeten worden gezet. Morele vorming beoogt natuurlijk geen eenheidsvisie bij de studenten te realiseren, laat staan op te leggen, omdat moreel handelen steeds mede afhankelijk is van de individuele situatie en de maatschappelijke context.

Ik concludeer dat de filosofiedocent een belangrijke rol heeft. In de volgende sectie zal ik dit verder uitwerken.

\section{Empirisch onderzoek naar effectieve filosofielessen}

Studenten zullen dus aan het denken moeten worden gezet. De volgende stap is om beter te begrijpen wat hier precies onder dit "denken" verstaan moet worden. Ik behandel dit aan de hand van denken als reflecteren, zoals besproken door John Dewey in paragraaf 4.1, en denken als dialogeren, zoals besproken door Hannah Arendt (Kienstra et al., 2014a,b; Kienstra, 2016; Le Coultre, 2021) in paragraaf 4.2.

\subsection{Denken als reflecteren}

In How we think legt Dewey uit wat hij onder het denken verstaat dat volgens hem in het onderwijs getraind zou moeten worden. Hij definieert reflective thought als "active, persistent and careful consideration of any belief or supposed form of knowledge in the light of the grounds that support it, and the further conclusions to which it tends" (Dewey, 1910/2007:7).

Dit soort denken komt overeen met de notie van kritiek maken en reflecteren in mijn eigen onderzoek naar effectief filosoferen (Kienstra, 2016; Kienstra et al., 2015). Ik betoog daar dat filosoferen zich op verschillende momenten in de les voordoet. Voor het kwalificeren van zo'n moment stellen we het Parelmodel voor. Parels hebben verschillende lagen en deze lagen van parelmoer staan voor vijf filosofische activiteiten: redeneren, analyseren, toetsen, kritiek maken en reflecteren. Deze activiteiten zijn geordend: redeneren bijvoorbeeld is van een "lagere" orde dan reflecteren, maar wordt daarbij wel verondersteld. Hoe meer lagen een parel heeft, hoe beter het typisch filosofische geraakt wordt. Afhankelijk van de laag kunnen we spreken van minder of meer effectief filosoferen. De glans van de parel wordt bereikt wanneer er gereflecteerd wordt.

Ter codering van de hogere lagen maakten we gebruik van de volgende omschrijvingen:

- Bij parellaag Toetsen: Waren er leerlingen die andermans standpunten of ideeën verdedigden?

- Bij Kritiek maken: Waren er leerlingen die andermans standpunten of ideeën aanvochten?

- Bij Reflecteren: Waren er leerlingen die hun eigen standpunten of ideeën aanvochten? 
We laten twee voorbeelden zien (Kienstra, 2016, 2021b:136-139). Het gaat om twee uitersten van het spectrum van effectief filosoferen dat loopt van redeneren tot reflecteren. Deze voorbeelden worden later in het artikel geanalyseerd. Het eerste voorbeeld is een gangbare filosofieles van docent Frans. Ter illustratie geven we een deel van deze les hier weer.

Een gangbare filosofieles van docent Frans

\section{Context}

Het gaat om een filosofieles van vijftig minuten in een 4 havo-klas met vijftien leerlingen, van wie twaalf meisjes. De opstelling is een bus-vorm. Er is een studiewijzer. De leerlingen zijn aangekomen bij hoofdstuk 9 uit Geluk en wijsheid voor beginners, dat handelt over inspraak. Docent Frans opent de les met de vraag: "Inspraak, hebben we dat op school?"

\section{Onderwijsleergesprek}

Er volgt een onderwijsleergesprek van veertien minuten. De docent stelt vragen, de leerlingen geven een antwoord. Een selectie:

Docent: Het gaat over inspraak. Ik vroeg me af of je ook in school inspraak hebt.

Leerling 1: We hebben eigenlijk niet zoveel inspraak op school, simpelweg: Morgen mogen we gewoon niet staken van de school.

Docent: $\quad$ En waarom mag je niet staken?

Leerling 1: Omdat de school niet democratisch genoeg is.

Docent: We zijn gewoon niet democratisch genoeg?

Leerling 1: Dat zijn we niet zo direct, maar indirect.

Docent: $\quad$ Ah ja, jij had graag gestaakt?

Leerling 1: $\quad$ Nee, niet echt.

Leerling 2: Waarom gaan jullie niet staken?

Docent: $\quad$ Morgen is het een scholierenstaking, opgeroepen door het laks.

Leerling 3: Onder begeleiding van leraren.

Docent: Onder begeleiding van leraren?

Leerling 4: Meneer, ik zeg: doen!

Docent: Ja, over niet al te lange tijd wordt er bedacht dat wij in plaats van zeven weken nog maar zes weken zomervakantie zullen hebben. Ja, maar dat geldt dan voor leraren, en dat kunnen ze dan wel anders indelen, die dagen voor die schoolvakantie. Scholen kunnen dan zeggen: dat doen we gewoon op andere momenten. En dan heb je dus bijvoorbeeld in mei een paar meer dagen vrij, en zulke dingen meer, en dan wordt het wat anders geregeld. Maar leraren krijgen een week minder vakantie. Er wordt niet aan ons gevraagd wat vinden wij ervan, of zo. Er wordt eigenlijk steeds minder aan ons gevraagd. Dat is wel een beetje triest. En er zitten vertegenwoordigers van ons in de $\mathrm{MR},{ }^{2}$ maar ja, daar horen we nooit wat van, toch een beetje triest, vind ik zelf. Maar over inspraak is wel filosofisch nagedacht: hoe kan je dat nou het best organiseren? 
Een effectieve les is de les van docent Marc. Ook van deze les geven we een deel weer.

Een effectieve filosofieles van docent Marc

\section{Context}

Marc geeft een filosofieles van vijftig minuten in een 5 vwo-klas met dertien leerlingen, allen meisjes. De opstelling is een U-vorm. De klas begint aan een nieuwe module philosophy of mind. Marc neemt met zijn leerlingen eerst de uitgedeelde reader door en geeft uitleg over de menselijke geest: wat is dat en hoe werkt het? Hij vertelt over Alan Turing en de turingtest. De opdracht luidt: kun je vragen bedenken om erachter te komen wie mens is en wie computer? Na verhelderingsvragen van de leerlingen, schrijven ze eerst (drie minuten) vragen voor zichzelf op. Vervolgens starten Marc en zijn leerlingen een filosofische discussie over het feit dat je ook bij een mens drie keer hetzelfde kan vragen (acht minuten). Daarna volgt een filosofische discussie (acht minuten). Hierna volgt daar een selectie uit.

\section{Gedachte-experiment}

Leerling 1: Ja, als je aan een computer vraagt: beschrijf mij nu eens zoals je nu tegen me aankijkt, dan moet de computer jou dus beoordelen op dat moment.

Docent: En waarom is dat een goede vraag eigenlijk?

Leerling 1: Omdat een mens mensenkennis heeft en een computer niet.

Docent: Dus het vertalen van de antwoorden die jij geeft naar wat voor persoon jij zou zijn, dat kan een mens wel, of redelijk, en voor een computer ... $\mathrm{Ja}$, dat is een veel te moeilijke vraag voor een computer, want die heeft geen mensenkennis, zeg jij. Ja, is dat een goed idee?

Leerling 1: Ja maar, nee oké, als jij mij vraagt: beschrijf mij eens in drie woorden, dan krijg ik altijd te horen: druk of grappig of zo, en dat kan een computer toch niet ... ja, maar als jij al de hele tijd aan het praten bent, dan kan een computer toch niet zeggen: stil!

Docent: $\quad$ Oké, dus hoewel je niet per se ervan uit hoeft te gaan dat je dan te maken hebt met een dom mens, want als je allerlei slimme antwoorden hebt gekregen, dan kan het zijn daarna dat hij dit toch een moeilijke vraag vindt. Dat kan een mens vinden, maar ook een computer ... Dus daarmee kan je het onderscheid niet maken, maar het gaat er jou vooral om dat het dus sowieso een computer niet zal lukken, omdat die gewoon geen mensenkennis heeft.

Leerling 1: Ja.

Docent: Ja...

Leerling 5: Maar kijk, die mens en die computer, die kennen jou alleen maar best objectief, zeg maar. Die kennen jou niet zoals jouw vriendin of jouw ouders je kennen. Ik zou daar ook niet uit op kunnen maken, als iemand mij gewoon zo'n vraag zou stellen, wat voor persoon dat was.

Om leerlingen te leren filosoferen is het wenselijk dat het filosoferen op een zo hoog mogelijk niveau plaatsvindt. Hoe je dit niveau bepaalt, bespreek ik in paragraaf 4.2. 


\subsection{Denken als dialogeren}

In haar onderzoek naar het denken constateert Arendt net als Dewey dat mensen het grootste deel van de tijd niet nadenken. Arendt benadrukt hierbij dat mensen handelen volgens gewoonten en gebruiken, en zich baseren op vooroordelen. Ik citeer Le Coultre (2021:116117):

De afwezigheid van het denken wordt een probleem in een crisissituatie, wanneer het erop aankomt om zelf tot het juiste oordeel te komen. In haar boek over het proces tegen ss-functionaris Eichmann typeerde ze diens gedachteloze opvolgen van bevelen als de 'banaliteit van het kwaad'. Hierin schuilt de morele betekenis van de rol van het denken bij Arendt, en hier komt de vraag uit voort die ze met haar onderzoek naar het denken wil oplossen: zou denkactiviteit de voorwaarde kunnen zijn waardoor mensen zich van het kwaad onthouden?

Vervolgens stelt Arendt dat denken pluraliteit veronderstelt, oftewel: andere mensen. Denken kan alleen in taal en taal is iets gemeenschappelijks. Taal is bestemd om gehoord te worden, woorden om begrepen te worden.

Kortom met taal communiceren we denkbeelden. Het denken vat Arendt daarom op als een dialoog. Dat sluit aan bij het uitgangspunt van het filosofieonderwijs in Nederland dat je leerlingen filosofie leert door ze te leren zelf te filosoferen. We vatten filosoferen daarbij van meet af aan op als een interactieve groepsactiviteit, daarom spreken we van filosoferen in de klas. Filosoferen als vita contemplativa valt buiten ons bestek (Kienstra, 2016:35).

Dit filosoferen in de klas hebben wij op verschillende manieren onderzocht. Via literatuuronderzoek hebben wij 30 filosofische werkvormen gevonden.

Enkele van de bekendere dialoogvormen zijn: brainstorm, socratisch gesprek, gedachteexperiment, speech, filosoferen met kinderen, onderwijsleergesprek en tetraloog. Deze 30 filosofische werkvormen hebben we geclusterd in 3 patronen van filosoferen om beter zicht te kunnen krijgen op hoe filosoferen in de klas nu werkt (Kienstra et al., 2014a,b). De 3 patronen zijn:

1) "filosoferen als verbindende waarheidsvinding":

Hierbij gaat men met elkaar in verhalen en gesprekken op zoek naar de waarheid

2) "filosoferen als toetsende waarheidsvinding":

Dit is kritisch onderzoeken en toetsen zoals ook in de wetenschappen gebeurt

3) "filosoferen als juridisch debat":

Aan het einde van een debat vindt er uiteindelijk een oordeel door een "rechter" plaats.

In "filosoferen als verbindende waarheidsvinding" lijkt filosoferen op spinnen en weven: degene die aan het woord is, reageert op zijn voorganger. De leerlingen komen samen tot meer inzicht en een gemeenschappelijk verhaal (vgl. Arendt, 1958).

Naast het literatuuronderzoek heb ik ook exploratief, observationeel onderzoek gedaan. In filosofielessen is gekeken hoe er wordt gefilosofeerd. We hebben dit in beeld gebracht met vragenlijsten, opnames en interviews. We hebben 3 dingen onderzocht, namelijk: het zelf filosoferen van de leerlingen, het docentgedrag in de filosofieles en de lesontwerpen (met de werkvormen gegroepeerd in de eerdergenoemde drie patronen en de inhoudelijke domeinen van de filosofie, zoals wijsgerige antropologie, kennisleer en ethiek). Er is kwalitatief en kwantitatief geanalyseerd. In de eerste plaats kijken we interpretatief, waarbij we cases hebben samengevat in een matrix die Miles en Huberman (1994) als metamatrix aanduiden. 
We hebben de kwantitatieve techniek correspondentieanalyse gebruikt om een plaatje van de metamatrix te maken. Je ziet dan dat de lessen op een lijn liggen, met links lessen waar het zelf filosoferen beter gaat, en rechts, waar het wat minder goed gaat. Uit de analyse blijkt dat, als de docent een filosofische discussie met gedeelde sturing voert, leerlingen parels produceren die langer duren en een hoger niveau hebben (Kienstra et al., 2015, Kienstra \& Van der Heijden, 2018).

We lichten het voorgaande toe aan de hand van de twee voorbeelden die we gaven aan het begin van deze paragraaf. Dit zijn de twee uiterste lessen op de lijn die we vonden in de correspondentieanalyse (Kienstra 2016, 2021b:152-153). Les 7 van docent Frans was de les die het laagst scoorde op effectiviteit. Ter illustratie geven we hier een nadere analyse van deze les weer.

Analyse van gangbare filosofieles 7 van docent Frans - parel 1

In deze parel is sprake van toetsen, want het begrip "inspraak" wordt in twijfel getrokken aan de hand van persoonlijke ervaring. Er is weinig wederzijdse inhoudelijke inbreng in de interactie: de leerlingen noemen het onderscheid tussen directe en indirecte democratie, maar de docent kiest een ander pad.

Les 2 van docent Marc was de les die het hoogst scoorde op effectiviteit. We geven ook een nadere analyse van deze les weer.

Analyse van effectieve filosofieles 2 van docent Marc - parel 3

In deze parel is sprake van reflecteren, omdat de laatste leerling op een hoog niveau nadenkt over de eerdere bijdragen aan de discussie. Eerst wordt de gedachte aangevallen dat er geen onderscheid is tussen een mens en een computer. Daarna wordt binnen het begrip "mens" onderscheid gemaakt tussen objecten en subjecten, waarmee de leerling zichzelf verklaart tot object (zoals een computer), als een onbekend persoon iets aan haar zou vragen. Hiermee denkt de leerling tegen zichzelf in, omdat de leerlingen zichzelf eerst niet vonden lijken op een computer. De leerlingen reageren authentiek met "Jajaja" en "druk, of grappig of zo". Docent Marc brengt ordening aan en laat leerlingen op elkaar reageren.

Ten tijde van de Atheense polis, waren "spreken in het openbaar, debat en filosofie" de hoekstenen van het democratische leven. Filosofie had de vorm van een dialoog tussen mensen met tegengestelde meningen, en filosofen onderwezen de kunst van het overtuigen aan burgers die de ekklesia bezochten, de belangrijkste vergadering van de democratie van het oude Athene. Tegenwoordig echter zijn op middelbare scholen debatclubs en filosofielessen gescheiden werelden geworden die elkaar helaas zelden ontmoeten. Deze situatie leidt tot een verspilling van kennis en vaardigheden. Het Erasmusplus project met de titel "A Debate And Philosophy Typologie" (ADAPT, 2021) beoogt de kloof tussen debatclubs en filosofielokalen te overbruggen door innovatieve onderwijsmaterialen te ontwikkelen en de effectiviteit ervan te onderzoeken. 
Hier komen we uit bij het antwoord op Arendts beginvraag of denkactiviteit de voorwaarde zou kunnen zijn waardoor mensen zich van het kwaad onthouden: uit dit denken, dialogeren, komt het geweten voort en het vermogen te oordelen. Eerder in dit paper heb ik aangegeven dat ethiek leren reikt van cognitief leren, via reflecteren en via oordelen, naar moreel handelen en morele vorming: learning ethics as knowledge-oriented, learning ethics as reflectionoriented, learning ethics as moral judgement-oriented en learning ethics as competencel action-oriented. Ik kom hier tot het volgende standpunt:

- $\quad$ effectief filosoferen kan geclassificeerd worden als: learning ethics as moral judgement-oriented. Dit is de eerste cognitieve en vaardigheidscomponent van morele vorming.

Er is ook een tweede component van morele vorming, namelijk een attitude component. Deze bespreek ik in de volgende paragraaf.

\section{Het goede doen als oefening die het karakter vormt}

Ik vervolg nu met een citaat waarin wordt aangegeven dat het goede doen niet (later) wordt toegevoegd aan theorie of discussie, maar dat het goede doen een echte oefening in de praktijk betreft die de mens ook transformeert, oftewel die het karakter ook echt vormt:

[An] important characteristic of leading a philosophical life is that practical exercises in wisdom are not something added to the philosophical praxis, complementing an abstract theory or discourse, but a philosophical life as such has to be conceived as a spiritual exercise. These exercises can be defined as 'a voluntary, personal praxis, meant to realize a transformation of the individual, a transformation of the self' [Hadot 2001:144]. This shows that the final aim of these exercises and, hence, of the schools of wisdom, is not so much to inform the disciples about philosophical theories and insights, but to (trans) form their lives, that is to educate them. (Jonkers, 2019:31)

Ik kom hiermee tot een tweede standpunt:

- het goede doen kan geclassificeerd worden als learning ethics as competence/actionoriented. Dit is de tweede attitude component van morele vorming.

Dit brengt ons bij een andere dimensie van de filosofie, die te maken heeft met de vraag of filosofie iets theoretisch is of eerder een houding, een attitude? Deze laatste is er volgens Ossewaarde-Lowtoo (2020:291) een van eerbied of ontzag. Zo'n houding gaat gepaard met (intellectuele) nederigheid en ontvankelijkheid voor wijsheid, maar ook met kritische alertheid. Hadot laat ons zien dat Aristoteles weliswaar een onderscheid maakt tussen theoretische en praktische wijsheid, maar dat dit zeker geen scheiding tussen de twee impliceert. Dat wil zeggen dat theoretische wijsheid niet volledig gescheiden is van het menselijk leven; evenzo is praktische wijsheid niet louter en alleen een toepassing van theoretische inzichten op de praktijk (Kienstra, 2020b:257). Moreel handelen en filosofie verlangen dus naast nadenken (na-denken is het motto van de Nederlandse Denker des Vaderlands 2021 Paul van Tongeren) ook action: een samengaan van kennis, inzicht, vaardigheden en attitudes. 


\section{Besluit}

Wat levert bovenstaande voor (nieuwe) inzichten op?

Zowel vanuit de literatuur als vanuit ons net genoemde onderzoek hebben we ontwerpprincipes voor effectieve, reflexieve, filosofielessen geformuleerd (Kienstra, 2016:130):

1. Schep onwetendheid (dus zorg ervoor dat studenten gaan twijfelen, dat is erg belangrijk bij filosofie).

2. Lok argumentaties van studenten uit (om een hoger niveau van filosoferen te bereiken).

3. Zorg ervoor dat studenten zelf een filosofische opvatting kunnen formuleren.

4. Doe 2 en 3 voortdurend.

5. Combineer verhalende met toetsende en met confronterende vormen van filosoferen.

6. Bespreek de inhoud en reflecteer hierop (immers filosofie leer je door zelf te filosoferen).

Alsof het een webwinkel betreft, kan gezocht worden naar geschikte lesmaterialen in alle vier manieren van ethiek leren op https://ethics.community.

\section{Een motiverend voorbeeld}

Zoals ik eerder heb laten zien, kun je er weliswaar van overtuigd zijn dat goede filosofie, zowel in academisch onderzoek, in de collegezalen als in het publieke debat, mensen stimuleert om kritisch en systematisch na te denken over dingen die ertoe doen, maar levert dat reflecteren nog niet zomaar moreel handelen op, laat staan goede mensen. Daarom heb ik een opdracht ontworpen, die wellicht met een geringe aanpassing ook in een andere faculteit zou kunnen worden uitgevoerd:

- Bereid een "goede (bijvoorbeeld tolerante, barmhartige) daad" voor

- Beargumenteer de specifiek gekozen deugd

- Beschrijf in de bijlage hoe de goede daad/handeling is verlopen

- Evalueer het werken aan je karaktervorming en het resultaat daarvan

- Reflecteer op de door jou gekozen deugd, zowel vanuit de theorie als vanuit de praktijk.

Ter illustratie geef ik een deel van een ingeleverde opdracht hier (enigszins geredigeerd) weer. ${ }^{3}$

Een andere ingeleverde opdracht is verschenen in de community van DeWereldMorgen.be, door Van der Aa (2021). 


\section{Bereid een "goede daad" voor}

Aziza wil om de deugd barmhartigheid te oefenen een dag naar het attractiepark en Sprookjesbos de Efteling met haar zus met een verstandelijke beperking gaan: ik wil leren om geduldig om te gaan met het menselijk tekort en om mijn eigen mening en opkomende emoties te beheersen. Wat ik ergerlijk vind aan mijzelf is dat dit voor mij moeilijk blijft en ik dit niet gewoon kan dulden en accepteren. Dit heeft, denk ik, met mijn karakter te maken. Ik ben veeleisend en direct en uit dit ook. Moyaert zegt heel terecht dat barmhartigheid niet alleen maar "mild zijn" is. Barmhartigheid is moeilijk, omdat een barmhartige houding de hoop op beterschap opgeeft.

\section{Beargumenteer de specifiek gekozen deugd}

Wanneer een persoon zich barmhartig toont, zal dit in een houding van dienstbaarheid gaan. Een houding waarin iemand zich ondergeschikt maakt aan de ander (Moyaert, 2007:718). Barmhartigheid begint wanneer de gebruikelijke rechtvaardigingsstrategieën en morele antwoorden opgehouden zijn en een persoon niet langer aangesproken kan worden op zijn of haar ethisch gedrag. Het is barmhartig om dan niet te vertrekken, maar te dulden (De Wit, 2009:49).

Barmhartigheid geneest niet en lost de problemen niet op. Hierin verschilt barmhartigheid ook van rechtvaardigheid. Rechtvaardigheid beoogt billijkheid te realiseren door alle mensen op gelijke wijze te belonen en te straffen. Barmhartigheid beseft dat het wreed is om voor alle mensen dezelfde maatstaf te nemen. Kort gezegd, barmhartigheid begint waar rechtvaardigheid haar grenzen bereikt.

\section{Beschrijf in de bijlage hoe de goede daad/handeling is verlopen}

Mijn geduld werd op het einde van de dag op de proef gesteld, toen mijn zus per se weer naar het winkeltje van de Efteling moest om nog wat te kopen. Op dat moment moest ik echt weer even diep ademhalen. Qua geld heeft ze ook geen besef van waarde en grens. Ze wilde nog een zuurstok kopen en dat hebben we gedaan. Dat was genoeg, hebben we tegen haar gezegd en dat accepteerde ze.

\section{Evalueer het werken aan je karaktervorming en het resultaat daarvan}

Ik besefte altijd al wel dat het niet goed was, zoals ik kon reageren op mijn zus, maar ik kon er nooit de vinger op leggen wat er nu precies gebeurde. Na het college en het lezen van de artikelen van Moyaert en De Wit begreep ik dat het gaat om de deugd barmhartigheid. Ik vond het een opluchting om te beseffen wat er in het geding is; dat het om een deugd gaat, waar je dus ook gewoon aan kan werken.

\section{Reflecteer op de door jou gekozen deugd, zowel vanuit de theorie als vanuit de praktijk}

In het artikel van Moyaert en De Wit lag er de nadruk op dat barmhartigheid met name wordt bewezen aan diegenen die moreel niet meer aanspreekbaar zijn. Ook degene die barmhartigheid bewijst, mag dit aan zichzelf bewijzen (ik mag dus ook wel wat barmhartiger voor mezelf zijn).

Zo kunnen we, ondersteund door onderzoek uit faculteiten waar karaktervorming tot de kern behoort, filosofie en theologie, werken aan de morele vorming van studenten. Niet alleen studenten en hun docenten zullen hiervan profiteren, maar ook de gemeenschap rond de studenten (bijvoorbeeld leeftijdgenoten en familie) en hun beroepspraktijken (pastoraat, justitie, defensie, geestelijke verzorging en onderwijs). 


\section{BIBLIOGRAFIE}

Aa, J-L van der. 2021. https://www.dewereldmorgen.be/community/besnik-en-een-sociale-filosofie-vande-barmhartigheid-een-kleine-etnografie/ [7 oktober 2021].

ADAPT. 2021. Erasmus+ project card | Erasmus+ (europa.eu) [6 mei 2021].

Arendt, H. 1958. The human condition. Chicago: University of Chicago Press.

Biesta, G. 2015. Het prachtige risico van onderwijs. Culemborg: Phronese.

COMET 1. 2021. https://ec.europa.eu/programmes/erasmus-plus/projects/eplus-projectdetails/\#project/7213ba12-efea-42f5-9e68-7a83f19052e7 [6 mei 2021].

COMET 2. 2021. Erasmus + project card | Erasmus+ (europa.eu) [6 mei 2021].

Derrida, J. 2005 (originally published in 1994). The politics of friendship. London: Verso.

Dewey, J. 1910/2007. How we think. Digireads.com Publishing.

Dijk-Groeneboer, M van. 2020. Memo Bestuurlijke reactie Visitatierapport Onderwijs. Aan: College van Bestuur. Datum: 29 september 2020.

Ethics community. 2021. http://www.ethics.community [26 april 2021].

Gayle, R. 2011. 'Befriending Wisdom', Analytic Teaching and Philosophical Praxis 31, 1:70-78, https:// journal.viterbo.edu/index.php/atpp/article/view/1053/867.

Hadot, P. 2001. La philosophie comme manière de vivre. Entretiens avec Jeannie Carlier et Arnold I. Davidson. Paris: Albin Michel.

Harrison, VS. 2020. Realigning Philosophy and Wisdom in the 21 st Century. Algemeen Nederlands Tijdschrift voor Wijsbegeerte, 112(3):325-40. DOI: 10.5117/ANTW2020.3.006.HARR.

Heijstek-Hofman, A, van Dijk-Groeneboer, MCH, \& van Amelsvoort, M. 2020. Persoonsgerichte burgerschapsvorming in het openbaar voortgezet onderwijs. Tydskrif vir Geesteswetenskappe, 60(3): 745-763. DOI:10.17159/2224-7912/2020/v60n3a11.

Jonkers, P. 2019. Philosophy and (Christian) Wisdom. In Philosophy as Love of Wisdom: Its Relevance to the Contemporary Crisis of Meaning, Council for Research and Values in Philosophy, pp. 41-60.

Kienstra, N. 2021b. Effectief filosoferen in de klas. In: Berendsen, D, Kienstra, N, Poortier, K \& Rombout, F (reds.). Filosofie op school. Handboek vakdidactiek filosofie. Amsterdam: Boom, pp. 135-161.

Kienstra, N. 2021a. De rol van de filosofieles en de filosofiedocent. In: Harlaar, M (red.), De getemde mens. Waar komt (volgens $u$ ) onze moraal vandaan? Antwerpen: Gompel\&Svacina, pp. 161-163.

Kienstra, N. 2020b. Reconnecting Wisdom and Philosophy. Algemeen Nederlands Tijdschrift voor Wijsbegeerte, 112(3):253-59. DOI: 0.5117/ANTW2020.3.001.KIEN.

Kienstra, N. 2020a. Ethics education in a globalized world: a community of ethics teachers in Europe (COMET). Age of globalization. Studies in contemporary global processes, 11(1):33:109-119.

Kienstra, N. 2019. Theologische bijdragen voor leraarschap. Tydskrif vir Geesteswetenskappe, 49:203215.

Kienstra, N \& Velema, F. 2019. ethics.community Exploring how ethics is taught in secondary schools across Europe. In: Association Internationale des Professeurs de Philosophie (eds), Identité - Identität - Identity, Europa Forum PHILOSOPHIE, bulletin 68, Verlag Traugott Bautz GmbH, pp. 26-37.

Kienstra, N \& Van der Heijden, PGM. 2018. Doing Philosophy Effectively II: A Replication and Elaboration of Student Learning in Classroom Teaching. PLoS ONE 13(12): e0208128. doi:10.1371/ journal.pone.0208128.

Kienstra, N, Van Dijk-Groeneboer, M \& Boelens, O. 2018. Religious-thinking-through using bibliodrama: An empirical study of student learning in classroom teaching, Religious Education. Doi:10.1080/ 00344087.2017.1403788.

Kienstra, N \& Velema, F. 2018. A Community of Ethics Teachers in Europe (COMET). In: Association Internationale des Professeurs de Philosophie (eds). Résistance - Widerstand, Europa Forum PHILOSOPHIE, bulletin 67, Verlag Traugott Bautz GmbH, pp. 171-180.

Kienstra, N. 2016. Effectief filosoferen in de klas. Docenten zelf lesontwerpen laten maken in het schoolvak filosofie. (Proefschrift Radboud Universiteit). Enschede: Ipskamp Printing.

Kienstra, N, Imants, J, Karskens, M \& Van der Heijden, PGM. 2015. Doing Philosophy Effectively: Student Learning in Classroom Teaching. PLOS ONE 10(9): e0137590. doi:10.1371/journal. pone. 0137590 . 
Kienstra, N, Karskens, M \& Imants, J. 2014b. Filosoferen in de klas: Een analyse van filosofische werkvormen/Doing philosophy in classroom teaching. Tydskrif vir Geesteswetenskappe, 54(4):787805 .

Kienstra, N, M Karskens \& J Imants. 2014a. Three Approaches to Doing Philosophy: a Proposal for Grouping Philosophical Exercises in Classroom Teaching. Metaphilosopy, 45(2):288-319.

Le Coultre, E-A. 2021. De pedagogische taak van de filosofiedocent: ruimte scheppen om te denken. In: Berendsen, D, Kienstra, N, Poortier, K \& Rombout, F (red.). Filosofie op school. Handboek vakdidactiek filosofie. Amsterdam: Boom, pp. 109-127.

Miles, MB \& Huberman, AM. 1994. Qualitative data analysis: An expanded sourcebook. Thousand Oaks: Sage.

Moyaert, P. 2007. Barmhartigheid: Transcendentie verdragen. Tijdschrift voor Filosofie, 69(4):713-732.

Nussbaum, MC. 2010. Not for Profit: Why Democracy Needs the Humanities. Princeton: Princeton University Press.

Ossewaarde-Lowtoo, R. 2020. Wisdom Begins with Awe. Algemeen Nederlands Tijdschrift voor Wijsbegeerte, 112(3):291-305. DOI: 10.5117/ANTW2020.3.

Rogers, JE. 2002. Longitudinal outcome assessment for forensics: Does participation in intercollegiate, competitive forensics contribute to measurable differences in positive student outcomes? Contemporary Argumentation and Debate, 23:1-27.

Schoone, J. 2021. Morele oordeelsvorming: tussen indoctrinatie en relativisme. In: Berendsen, D, Kienstra, N, Poortier, K \& Rombout, F. (reds.). Filosofie op school. Handboek vakdidactiek filosofie. Amsterdam: Boom, pp. 303-310.

TEP. 2021. Tilburg Educational Profile. http://www.tilburguniversity.edu/about/education/tep [26 april 2021].

TiU. 2021. Homepage Tilburg University. http://www.tilburguniversity.edu/nl [26 april 2021].

Valkering, A, Nemčok, M \& Matu, G. 2017. From Measuring to Learning: Evaluating the Impact of Debate on Critical Thinking and Democratic Values. https://idebate.org/news/idea-nl-launchesstudy-impact-debate-education [13 mei 2021].

Van de Pol, J, M Volman \& J Beishuizen. 2011. Patterns of contingent teaching in teacher-student interaction, Learning and Instruction, 21:46-57.

Van de Pol, J, M Volman \& J Beishuizen. 2010. Scaffolding in teacher-student interaction: A decade of research, Educational Psychology Review, 22:271-296.

Werkgroep 'Karakter'. 2018. Karaktervormingsleerlijn (KVL) BA-Theologie. Eindrapport. Utrecht: Tilburg School of Catholic Theology.

Wit, T de. 2009. De gewonde gemeenschap. Over barmhartigheid en gevangenschap. In: AHM van Iersel \& JDW Eerbeek (reds.). Handboek justitiepastoraat Context, theologie en praktijk van het protestants en rooms-katholiek justitiepastoraat, Eindhoven: Damon, pp. 31-55. 